\title{
Arachnoid clearance of red blood cells
}

\author{
J. D. MCQUEEN, B. E. NORTHRUP, AND L. G. LEIBROCK \\ From the Baltimore City Hospitals, Perry Point Veterans Administration Hospital, \\ the Department of Neurosurgery, Johns Hopkins University School of Medicine, \\ Baltimore, Maryland, U.S.A.
}

SYNOPSIS Labelled red blood cells were instilled intraventricularly in groups of dogs and monkeys for evaluation of transfer to the vascular compartment. Blood levels were minimal $(5 \%$ of the original material) with low-pressure infusions. A large movement (above $25 \%$ ) of the type originally described by Simmonds occurred with high-pressure intraventricular infusions, cisternal injections, or after the induction of intracranial hypertension. Large amounts of the label were released after cell lysis and accumulated in various tissues. Five to ten per cent of the instilled material was absorbed by the nasal lymphatic route in the dog and a significant local loss of red cells occurred after posterior cisternal punctures. Simulated whole blood was useful in demonstrating arachnoid retention, Ventriculospinal washouts aided in the elimination of tagged cells only in the first 24 hours. Thereafter, the yield was small and the fluid requirement was unusually high.

Unusually large variations in the movement of red cells from the subarachnoid space to the blood stream have been reported. The initial work of Simmonds indicated the transfer of approximately $15 \%$ of cisternal blood deposits (Simmonds, 1952, 1953). Other later studies disclosed a range extending from $2-66 \%$ (Adams and Prawirohardjo, 1959; Dupont et al., 1961; Bradford and Johnson, 1962). In this work, we have re-evaluated the removal of subarachnoid blood by (1) testing the influences of hydrostatic force and of lavage, (2) measuring the uptake of radioactive label in various tissues, and (3) comparing the results with the use of red cell suspensions and simulated whole blood.

\section{METHOD}

Forty-eight dogs and six monkeys were used and were observed under light barbiturate anaesthesia (pentobarbitone $25 \mathrm{mg}$ per $\mathrm{kg}$ ) with curarization (gallamine triethiodide $1 \mathrm{mg}$ per $\mathrm{kg}$ ), and when artificially ventilated with a Harvard respirator. The ventricular route was used for most red cell instillations, since it was found at the onset that large numbers of red cells were lost locally after punctures of the cisterna magna. A fenestrated 20 gauge cannula was used and was inserted stereotaxically into a lateral ventricle at a point $6.5 \mathrm{~mm}$ lateral to the mid- line and $15 \mathrm{~mm}$ anteriorly to the interaural line and at a depth of $22 \pm 2 \mathrm{~mm}$ from the outer surface of the skull. Autogenous red blood cells were chromated (Albert, 1971) and then diluted with an equal amount of saline to permit ready flow through the ventriculare system. Two millilitres of these suspensions were delivered to groups of dogs and macaque monkeys at

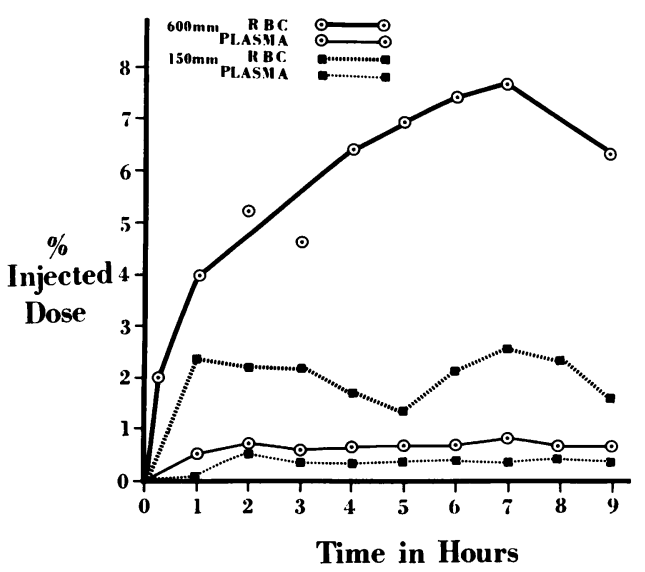

FIG. 1. Transfer of labelled red cells from the subarachnoid space to the vascular compartment in the dog. The effects of high and low infusion pressure are contrasted in two experiments. 


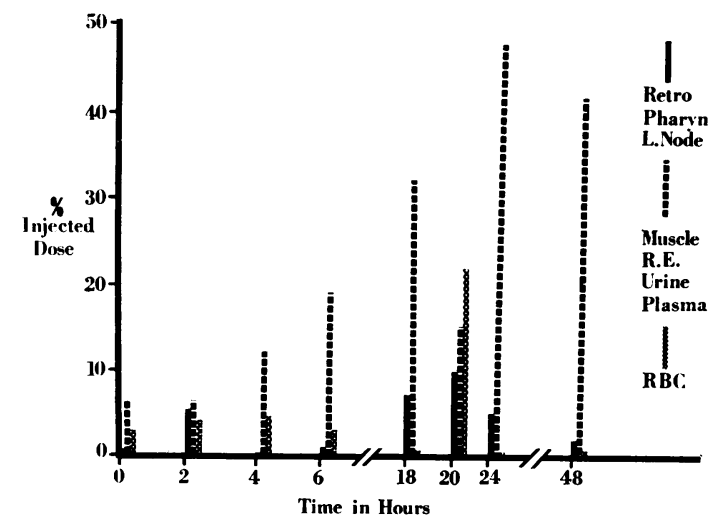

FIG. 2. Transfer of intraventricular infusion at a pressure of $150 \mathrm{~mm} \mathrm{H}_{2} \mathrm{O}$. Individual experiments are shown for the dog in this and following figures. Three major systemic areas are included: cervical lymph nodes, reticuloendothelial and other tissues, and the vascular compartment. Note the high tissue levels.

a constant pressure of $150 \mathrm{~mm} \mathrm{H}_{2} \mathrm{O}$ above the interaural line. Another group of dogs received similar suspensions at a pressure of $600 \mathrm{~mm} \mathrm{H}_{2} \mathrm{O}$.

Injections of simulated whole blood were used in a final group of dogs. For this, $1 \mathrm{ml}$ tagged cells were mixed with $3 \mathrm{ml}$ freshly drawn and untreated blood. This was injected promptly into the chiasmatic cistern at a peak pressure of $100 \mathrm{mmHg}$ with the paraocular puncture technique (McQueen and Jeanes, 1962). Observation periods varied from two to 48 hours. Serial blood samples were drawn during this interval. Red cells were spun down; their radioactivity and that of plasma was measured with a well

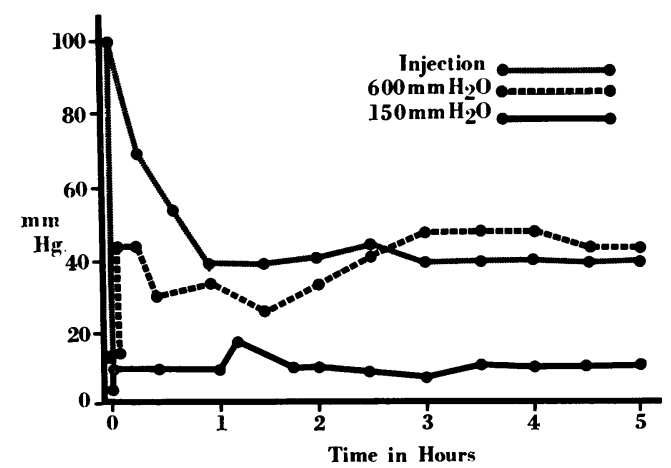

FIG. 3. Intraventricular pressures. Individual experiments are indicated for the three types of instillation. Zero time marks the end of the infusion or injection. Note the sustained pressure effect with the upper two. counter. Intraventricular pressures were monitored on a polygraph.

Two types of mock cerebrospinal fluid infusions were used at the end of the observation periods. Internal lavage was instituted first with a two hour intraventricular infusion at a pressure of $600 \mathrm{~mm}$ $\mathrm{H}_{2} \mathrm{O}$. Blood samples were counted every 15 minutes to evaluate facilitation of transfer to the vascular compartment.

An external lavage (spinal washout) was carried out immediately afterwards. Cerebrospinal fluid was evacuated through a small intrathecal catheter which was introduced and secured after a lumbar laminectomy. This fluid was counted and ventriculospinal lavage was carried out with large amounts of mock cerebrospinal fluid (Elliott and Jasper, 1949) which flowed for one hour at a pressure of $300 \mathrm{~mm} \mathrm{H}_{2} \mathrm{O}$. Blood sampling continued. The animals were killed with intracardiac $\mathrm{KCl}$ and cervical lymph nodes were removed to assess spread via the nasal lymphatics. These and a 2 litre blood washout from an aortic catheter, plus urine and samples of all major organs, were counted. Other technical details are given elsewhere (McQueen and Jelsma, 1967; McQueen et al., 1972).

\section{RESULTS}

Meagre levels of radiochromate appeared in the blood stream after low pressure, intraventricular instillations (Figs 1 and 2). This activity was below $5 \%$ of the injected dose. It appeared during the infusions and did not rise progressively during observation periods of 48 hours. There were two exceptions. Blood levels of 13 and $20 \%$ were noted in one dog and one monkey respectively. In both instances, intraventricular

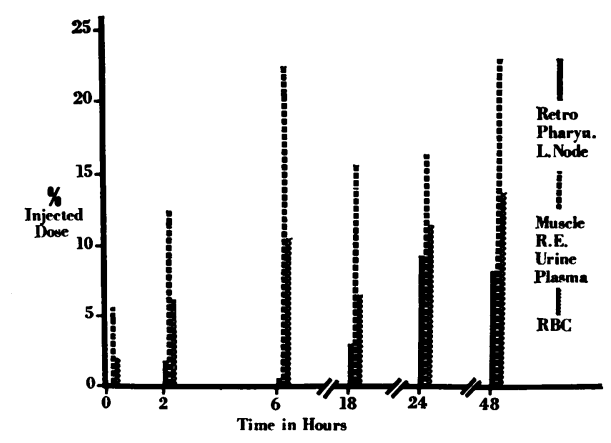

FIG. 4. Transfer of intraventricular infusion at a pressure of $600 \mathrm{~mm} \mathrm{H}_{2} \mathrm{O}$ in the dog. For comparison with Fig. 2. 


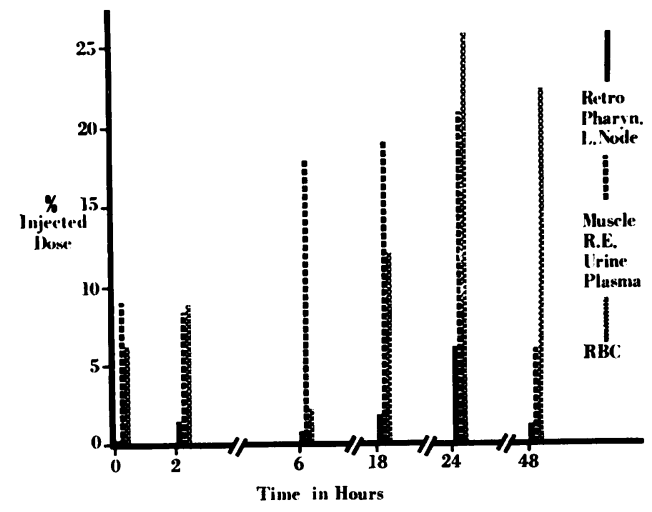

FIG. 5. Transfer of simulated whole blood injection. This was delivered via the chiasmatic cistern. For comparison with Figs 2 and 4.

pressures did not remain in the normal range as in other members of these groups but rose to a height of $300-500 \mathrm{~mm} \mathrm{H}_{2} \mathrm{O}$ and remained elevated until the time the animals were killed at 18 hours. Cerebrospinal fluid pressures are indicated in Fig. 3.

The patterns with the use of high-pressure (600 $\mathrm{mm} \mathrm{H}_{2} \mathrm{O}$ ) intraventricular infusions and with intracisternal injections were different (Figs $1,4,5)$. The rises were progressive and of the type originally described by Simmonds (1953). The average blood levels were $8.6 \%$ for infusions and $12.7 \%$ for injections; a peak level of $25.7 \%$ was found in one injected animal. Only one low concentration was noted.

Simulated whole blood injections augmented

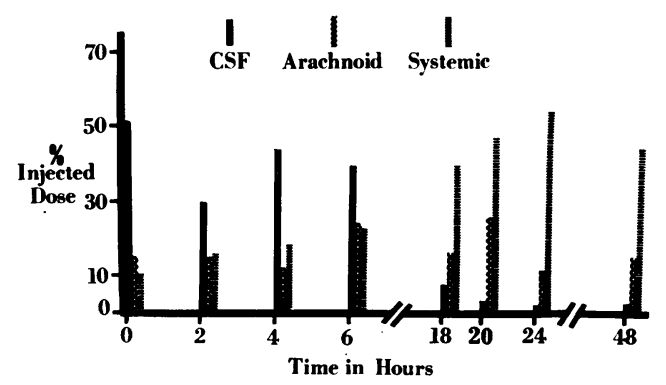

FIG. 6. Low-pressure infusion at $150 \mathrm{~mm} \mathrm{H}_{2} \mathrm{O}$ to demonstrate effect of ventriculospinal lavage. ' $C S F$ ' includes washout. 'Arachnoid' indicates retained material and 'systemic' designates transferred label.

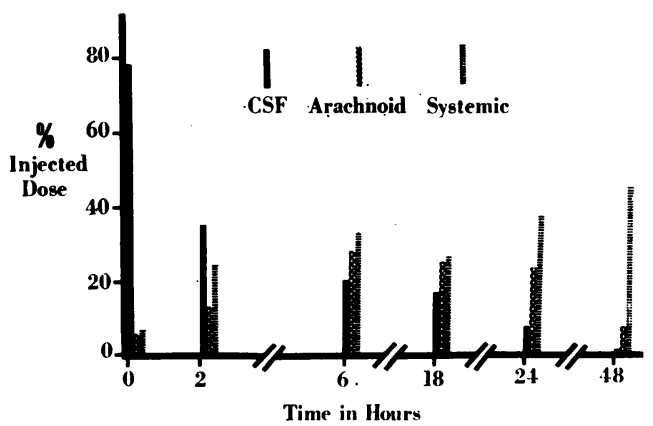

FIG. 7. High-pressure infusion at $600 \mathrm{~mm} \mathrm{H}_{2} \mathrm{O}$ for comparison with Fig. 6.

the usage of red cell infusions, and were particularly valuable in demonstrating retention within the cranial and spinal arachnoid mesh. These accumulations constituted $20-30 \%$ of the in jected dose; they remained after extensive ven triculospinal washouts and were much above $+\vec{N}$ those found after infusions (Figs 6, 7, 8).

Samples of plasma, urine, and various tissueso $\vec{\sigma}$ yielded significant counts of the isotopic label $\stackrel{\rho}{\mathrm{D}}$ 음 Figure 2 illustrates the large systemic deposits occurring with infusions at a pressure of $150 \mathrm{~mm}$ $\mathrm{H}_{2} \mathrm{O}$. This recovery was in the range $40-50 \%$ after 18 hours and exceeded blood levels. Liver and spleen contained prominent deposits as diđâ muscle and bone marrow; smaller amounts were found in other tissues. The label was also collected in (cell-free) urine samples which were incomplete since the animals were not maintained in metabolism cages. However, amounts equalling 9 and $10.5 \%$ of the original material

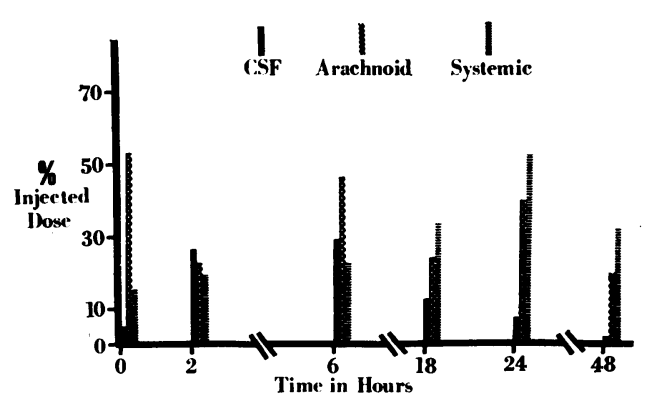

FIG. 8. Chiasmatic cisternal injection of simulated whole blood. For comparison with Figs 6 and 7. Note the significant arachnoid retention. 


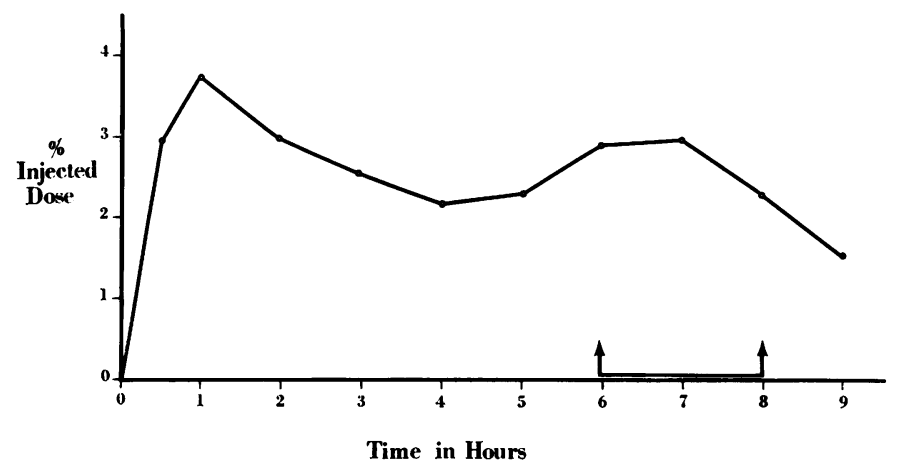

FIG. 9. Internal lavage (with no washout). The dog was used in this and following figures. Mock CSF was instilled at a pressure of $600 \mathrm{~mm} \mathrm{H}_{2} \mathrm{O}$ during the two hour period indicated by the arrows. Note the minimal effect on blood levels.

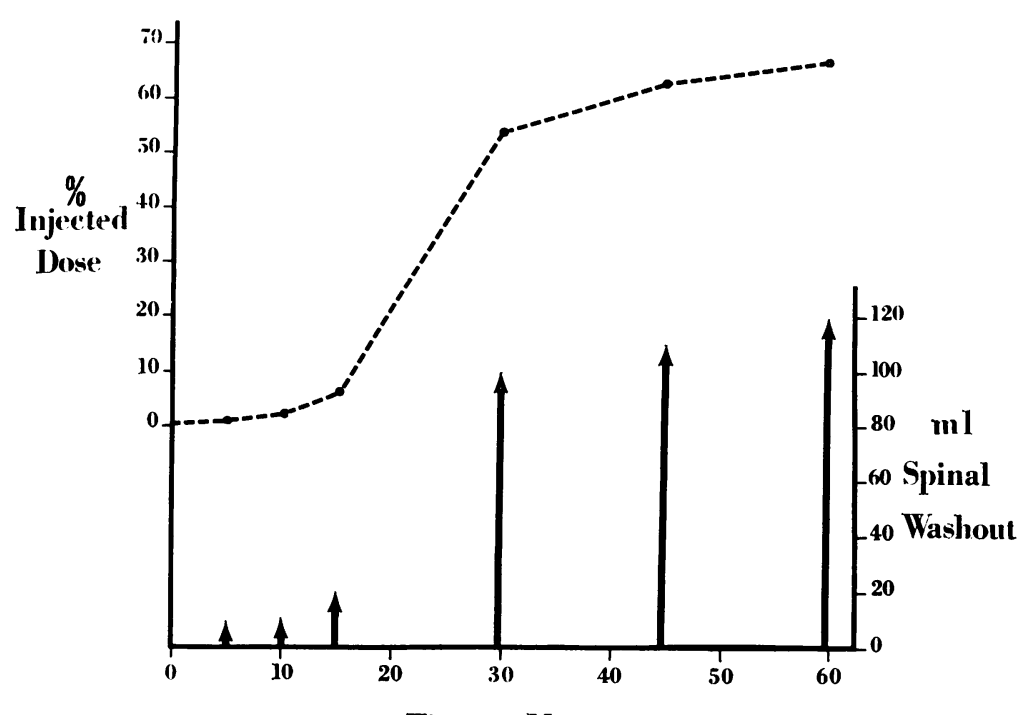

FIG. 10. Ventriculospinal lavage at two hours after red cell infusion. The recovery is indicated above. Note the meagre early return and the large fluid requirement.

Time in Minutes

appeared in two animals killed at 18 and 24 hours. Plasma activity was detected in all samples. Similar findings are shown in Figs 4 and 5 with other instillations.

The escape of cerebrospinal fluid through nasal lymphatics is well-known in the dog and was evaluated by removing and counting cervical lymph nodes. Radioactivity was confined to the middle retropharyngeal nodes and accounted for $5-10 \%$ of the instilled chromate. Efferent ducts were cannulated and radioactivity was not recovered. All cervical nodes were negative in the monkey.

Lavage techniques were tested in an attempt to mobilize the red cell deposits. Internal lavage (without washout) was utilized first and main- tained at $600 \mathrm{~mm} \mathrm{H}_{2} \mathrm{O}$ for periods of two hours. The immediate influences soon after the time of intracranial instillations were indeterminate because of spontaneous rises in radioactivity; 13 later lavages were scrutinized and positive effects were found only in six. This influence was minimal with elevations of blood levels in the range $0.4-3.5 \%$. One is shown in Fig. 9.

External drainage was accomplished with ventriculospinal perfusions. The total activity in these is indicated as cerebrospinal fluid in Figs 6,7 , and 8 . The spinal washout collected two hours after an intraventricular infusion of red cells in one animal is shown in Fig. 10, and illustrates the fact that small numbers of tagged cells appeared with drainage of fluid equal to the 


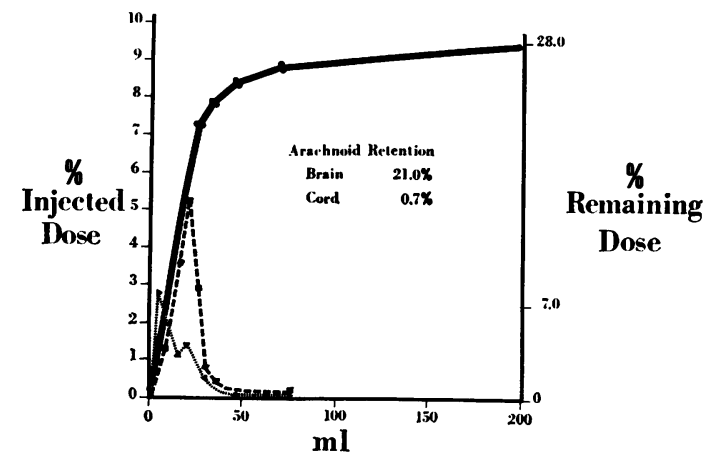

FIG. 11. Ventriculospinal lavage at 24 hours after red cell infusion. The heavy line indicates the relatively small total recovery. The small spiked line to the left depicts counts from samples of supernatant; the larger spiked line counts from intact cells. Arachnoid retention: brain, $21.0 \%$; cord, $0.7 \%$.

normal volume of cerebrospinal fluid. Significant amounts appeared with the use of more fluid and are shown on the right. Fluid requirements were high; minimal amounts of 15 and $40 \mathrm{ml}$ for the monkey and dog respectively were required to remove $80 \%$ of the available radioactivity. Relatively little radioactivity was recovered after the first 18 to 24 hours. The major problem of retentivity with later external lavages is illustrated in Fig. 11. This graph indicates that only a third of the remaining material was washed out at 24 hours and that over $95 \%$ of the retention was in brain as compared with cord. Counts from the supernatant peaked initially in the effluent; later, higher counts were recorded from intact cells.

\section{DISCUSSION}

The finding by Simmonds (1952, 1953) of a transfer of red cells from subarachnoid to vascular compartments supports the concept of arachnoid filtration originally offered by Key and Retzius (1876) and parallels the demonstrations of transdural flow by Hill (1896), and the flow through arachnoid villi by Welch and Friedman (1960), Welch and Pollay (1961), and Pollay and Welch (1962). It is substantiated by the physiological studies of Davson et al. (1970), but is unconfirmed on the electron micrographs of Alksne and Lovings (1972), and Shabo and
Maxwell (1968a, b), which depict no interruptions in the membranes about villi.

We evaluated arachnoid porosity with the use of the dissecting microscope and were able to follow the passage of thin, tinted oil into the sagittal sinus (McQueen et al., 1972). The fact that this in vitro flow required a pressure of 400 $\mathrm{mm} \mathrm{H}_{2} \mathrm{O}$ prompted this in vivo assessment.

The influence of hydrostatic force was stressed by Key and Retzius (1876) as they observed the effect of injection pressure in distending arachnoid granulations. Pressure-flow relationships for the transfer of Ringer's or Locke's solutions out of the subarachnoid space or across villi have been documented by Mortensen and Weed (1934) and by Welch and Friedman (1960). Similarly, the direct effect of pressure on the movement of red cell suspensions has been shown by Kennedy (1967).

Three aspects of the influence of hydrostatic force are stressed here. The first is the recordinge $\vec{N}$ of a minimal transfer of cells at low infusionc $\vec{\omega}$ pressures. This parallels the low blood levels in the studies of Dupont et al. (1961), and indicates? that relatively few intact cells enter the vascularo compartment after some subarachnoid haemor $\%$ rhages. Shabo and Maxwell (1968a) have sug 8 gested that hydrostatic force may rupture the $\frac{1}{3}$ arachnoid covering to account for cell move흐응 ment. This traumatic effect is difficult to dis $=$ prove in studies in the postmortem period; however, it would not account for the small but definite number of cells which appeared in the blood stream with essentially normal pressures in the current study.

The second feature is the irregularity in the transfer of erythrocytes. This may be a manifestation of the dual effects of hydrostatic pressure in moving red cells to and through villi and also in promoting a blockade to the passage of other cells or fluid (McQueen and Jelsma, 1967). Simulated whole blood was useful in demonstrating this second action. The enhanced arachnoid deposits emphasize the retentivity and their presence implies that this may be significantly greater than that recorded with the commonly used suspensions.

The third feature is the movement of red cells with three separate forces. These are the pressures associated with (1) the initial red cell infusion, (2) the later mock cerebrospinal fluid 
infusion, and (3) intracranial hypertension caused by arachnoid blockade.

There is no direct evidence to indicate that our labelled cells traversed villi but other routes are improbable since the removal of radioactivity was not detected from cervical lymph nodes and because the nasal escape noted in the dog by Di Chiro et al. (1972) was avoided with the use of monkeys. Similarly, the isotopic tag was in the reduced form and hence not able to label cells secondarily.

The deposits of radiochromate in tissues were high and could not be accounted for on the basis of sequestration of red cells since liberal amounts of terminal vascular perfusions were used to confirm the in vivo blood levels. The release was also much above that found with normal elution of the label (Burkle, 1964). These accumulations point to a local loss and escape of the label after red cell lysis. Probably a second release of isotope occurred after incorporation into reticuloendothelial tissues; unfortunately, the two cannot be separated in this study.

Ventriculospinal lavages with mock cerebrospinal fluid were effective in removing red cells only during the first $18-24$ hours. This recovery is much more limited than that found by Kennady (1967) and the current data indicate that the recovery is restricted to less than $10 \%$ of the initial dosage after 24 hours and that the fluid requirement for this washout is high. This limitation appears to be an extension of the conclusion recorded by Meredith (1941) and by Sprong (1934) who found repeated lumbar punctures to be ineffective in the elimination of subarachnoid blood.

We are greatly indebted to Mr Kevin Morooney and Mrs Carol Mann for their skilled assistance.

\section{REFERENCES}

Adams, J. E., and Prawirohardjo, S. (1959). Fate of red blood cells injected into cerebrospinal fluid pathways. Neurology (Minneap.), 9, 561-564.

Albert, S. N. (1971). Blood Volume and Extracellular Fluid Volume, 2nd edn. Thomas: Springfield, Ill.

Alksne, J. F., and Lovings, E. T. (1972). Functional ultrastructure of the arachnoid villus. Archives of Neurology, 27, 371-377.

Bradford, F. K., and Johnson, P. C., Jr (1962). Passage of intact iron-labeled erythrocytes from the subarachnoid space to systemic circulation in dogs. Journal of Neurosurgery, 19, 332-336.

Burkle, J. S. (1964). Radioisotopic measurement of erythrocyte lifespan. In Hemoglobin. Its Precursors and Metabolites, pp. 292-294. Edited by F. W. Sunderman and F. W. Sunderman, Jr. Lippincott: Philadelphia.

Davson, H., Hollingsworth, G., and Segal, M. B. (1970). The mechanism of drainage of the cerebrospinal fluid. Brain, 93, 665-678.

Di Chiro, G., Stein, S. C., and Harrington, T. (1972) Spontaneous cerebrospinal fluid rhinorrhea in normal dogs. Radioisotope studies of an alternate pathway of CSF drainage. Journal of Neuropathology and Experimental Neurology, 31, 447-453.

Dupont, J. R., Van Wart, C. A., and Kraintz, L. (1961). The clearance of major components of whole blood from cerebrospinal fluid following simulated subarachnoid hemorrhage. Journal of Neuropathology and Experimental Neurology, 20, 450-455.

Elliott, K. A. C., and Jasper, H. H. (1949). Physiological salt solutions for brain surgery. Journal of Neurosurgery, 6, 140-152.

Hill, L. (1896). The Physiology and Pathology of the Cerebral Circulation. An Experimental Research. Churchill: London.

Kennady, J. C. (1967). Investigations of the early fate and removal of subarachnoid blood. Pacific Medicine and Surgery, 75, 163-168.

Key, A., and Retzius, G. (1876). Studien in der Anatomie des Nervensystems und des Bindegewebes. Halfte 2, Abt. 1. Samson and Wallin: Stockholm.

McQueen, J. D., and Jeanes, L. D. (1962). Influence of hypothermia on intracranial hypertension. Journal of Neurosurgery, 19, 277-288.

McQueen, J. D., and Jelsma, L. F. (1967). Intracranial hypertension. Cerebrospinal fluid pressure rises following intracisternal infusions of blood components in dogs. Archives of Neurology, 16, 501-508.

McQueen, J. D., Northrup, B. E., Leibrock, L. G., and Morooney, K. (1972). The sealing action of subarachnoid blood. Symposium on the Cerebrospinal Fluid in Health and Disease. Edited by A. E. Walker and R. Arana Iñiquez. Acta Neurologica Latinoamericana, suppl. 1, 8798.

Meredith, J. M. (1941). The inefficacy of lumbar puncture for the removal of red blood cells from the cerebrospinal fluid. Surgery, 9, 524-533.

Mortensen, O. A., and Weed, L. H. (1934). Absorption of isotonic fluids from the subarachnoid space. American Journal of Physiology, 108, 458-468.

Pollay, M., and Welch, K. (1962). The function and structure of canine arachnoid villi. Journal of Surgical Research, 2, 307-311.

Shabo, A. L., and Maxwell, D. S. (1968a). The morphology of the arachnoid villi: a light and electron microscopic study in the monkey. Journal of Neurosurgery, 29, 451-463.

Shabo, A. L., and Maxwell, D. S. (1968b). Electron microscopic observations on the fate of particulate matter in the cerebrospinal fluid. Journal of Neurosurgery, 29, 464-474.

Simmonds, W. J. (1952). The absorption of blood from the cerebrospinal fluid in animals. Australian Journal of Experimental Biology and Medical Science, 30, 261-270.

Simmonds, W. J. (1953). The absorption of labelled erythrocytes from the subarachnoid space in rabbits. Australian Journal of Experimental Biology and Medical Science, 31, 77-83.

Sprong, W. (1934). The disappearance of blood from the cerebrospinal fluid in traumatic subarachnoid hemorrhage. Surgery, Gynecology and Obstetrics, 58, 705-710.

Welch, K., and Friedman, V. (1960). The cerebrospinal fluid valves. Brain, 83, 454-469.

Welch, K., and Pollay, M. (1961). Perfusion of particles through arachnoid villi of the monkey. American Journal of Physiology, 201, 651-654. 